Research

Open Access

\title{
Acute renal failure - definition, outcome measures, animal models, fluid therapy and information technology needs: the Second International Consensus Conference of the Acute Dialysis Quality Initiative (ADQI) Group
}

\author{
Rinaldo Bellomo ${ }^{1}$, Claudio Ronco ${ }^{2}$, John A Kellum ${ }^{3}$, Ravindra L Mehta ${ }^{4}$, Paul Palevsky ${ }^{5}$ and the \\ ADQI workgroup 6
}

\author{
1Department of Intensive Care and Medicine, Austin Health, Melbourne, Australia \\ 2Department of Nephrology, San Bortolo Hospital, Vicenza, Italy \\ ${ }^{3}$ Departments of Critical Care Medicine and Medicine, University of Pittsburgh Medical Center, and Renal Section, VA Pittsburgh Healthcare System, \\ Pittsburgh, Pennsylvania, USA \\ ${ }^{4}$ Department of Medicine, University of California, San Diego, California, USA \\ ${ }^{5}$ Department of Medicine, University of Pittsburgh Medical Center, and Renal Section, VA Pittsburgh Healthcare System, Pittsburgh, Pennsylvania, \\ USA \\ ${ }^{6}$ For a complete list of authors, see Appendix 1
}

Corresponding author: Rinaldo Bellomo, rinaldo.bellomo@austin.org.au

Received: 27 March 2004

Accepted: 22 April 2004

Published: 24 May 2004
Critical Care 2004, 8:R204-R212 (DOI 10.1186/cc2872)

This article is online at: http://ccforum.com/content/8/4/R204

(c) 2004 Bellomo et al.; licensee BioMed Central Ltd. This is an Open Access article: verbatim copying and redistribution of this article are permitted in all media for any purpose, provided this notice is preserved along with the article's original URL.

\begin{abstract}
Introduction There is no consensus definition of acute renal failure (ARF) in critically ill patients. More than 30 different definitions have been used in the literature, creating much confusion and making comparisons difficult. Similarly, strong debate exists on the validity and clinical relevance of animal models of ARF; on choices of fluid management and of end-points for trials of new interventions in this field; and on how information technology can be used to assist this process. Accordingly, we sought to review the available evidence, make recommendations and delineate key questions for future studies. Methods We undertook a systematic review of the literature using Medline and PubMed searches. We determined a list of key questions and convened a 2-day consensus conference to develop summary statements via a series of alternating breakout and plenary sessions. In these sessions, we identified supporting evidence and generated recommendations and/or directions for future research.

Results We found sufficient consensus on 47 questions to allow the development of recommendations. Importantly, we were able to develop a consensus definition for ARF. In some cases it was also possible to issue useful consensus recommendations for future investigations. We present a summary of the findings. (Full versions of the six workgroups' findings are available on the internet at http://www.ADQI.net)

Conclusion Despite limited data, broad areas of consensus exist for the physiological and clinical principles needed to guide the development of consensus recommendations for defining ARF, selection of animal models, methods of monitoring fluid therapy, choice of physiological and clinical end-points for trials, and the possible role of information technology.
\end{abstract}

Keywords: acute renal failure, animal models, creatinine, glomerular filtration rate, information technology, intravenous fluids, kidney, outcome research, randomized controlled trials, urea

$\mathrm{ARF}=$ acute renal failure; $\mathrm{ESRD}=$ end-stage renal disease; GFR = glomerular filtration rate; $\mathrm{MDRD}=$ modification of diet in renal disease; RIFLE $=$ Risk of renal dysfunction, Injury to the kidney, Failure of kidney function, Loss of kidney function and End-stage kidney disease; RRT = renal replacement therapy. 


\section{Introduction}

Acute renal failure (ARF) is a common complication of critical illness, which is associated with high mortality and has a separate independent effect on the risk of death [1,2]. Despite several advances in treatment and in our understanding of the pathogenesis of ARF, many aspects in this field remain subject to controversy, confusion and lack of consensus. Important aspects beset by such problems include the definition of ARF [3]; the choice, validity and relevance of animal models of ARF [4]; and the choice regarding appropriate physiological and clinical end-points for trials of new treatments of ARF [5]. They also include principles that should govern fluid management in patients with ARF [6] and use of information technology to optimize all areas of patient care in this field.

The purpose of this consensus conference was to review the available evidence regarding optimal practice in these areas, make consensus-based recommendations and delineate key questions for future studies.

\section{Methods}

Our consensus process relied on evidence where available and, in the absence of evidence, consensus expert opinion when possible [7]. This combined approach has previously led to important practice guidelines that were widely adopted into clinical practice [8]. In contrast, expert opinion alone can ignore important evidence, whereas evidence-based reviews can be conceptually flawed without expert opinion [9]. We conducted the consensus process in three stages: preconference, conference and postconference.

Before the conference, we identified six topics relevant to the field of ARF: definition/classification system for ARF; clinical outcome measures for ARF studies; physiological end-points for ARF studies; animal models of ARF; techniques for assessing and achieving fluid balance in ARF; and information technology in acute dialysis. We selected these topics based on the level of possible clinical impact, the level of controversy, known or suspected variation in practice, potential importance for scientific outcome, potential for development of evidencebased medicine recommendations, and availability of evidence. For each topic we outlined a preliminary set of key questions. We then invited an international panel, predominantly from the fields of nephrology and intensive care, based on their expertise in the fields of analysis. Panelists were assigned to three-person workgroups, with each workgroup addressing one key topic. Each workgroup conducted literature searches related to their topic questions via Medline, PubMed, bibliography of review articles and participants' files. Searches were limited to English language articles. However, articles written in other languages were used when identified by workgroup members. During this stage, the scope of the conference was also more clearly defined.
We conducted a 2-day conference in May 2002 in Vicenza, Italy. We developed summary statements through a series of alternating breakout and plenary sessions. In each breakout session, the workgroup refined key questions, identified the supporting evidence, and generated recommendations and/or directions for future research as appropriate. We generated future research questions by identifying deficiencies in the literature and debating whether more evidence was necessary. Where possible, we also considered pertinent study design issues. Workgroup members presented their findings during plenary sessions, rotating responsibility for presenting to ensure full participation. The workgroup then revised their drafts as needed until a final version was agreed upon. When consensus was not achieved on any individual question by the conclusion of the meeting, deliberations continued by correspondence. When voting was required to settle an issue, a two-thirds majority was required to approve a proposal.

A writing committee assembled the individual reports from the workgroups and each report was edited to conform to a uniform style and for length. Finally, each report was submitted for comments to independent international experts. In this report we present a summary of the proceedings.

\section{Results}

We achieved sufficient consensus for a total of 47 questions. We report a summary of the questions, proceedings and final recommendations for each individual workgroup below. A complete report of the findings, including a full discussion of the issues involved, along with rationale and independent comments by other international experts, can be found on the internet at the Acute Dialysis Quality Initiative (ADQI) Group website http://www.ADQl.net.

\section{Definition/classification system for acute renal failure}

The clinical condition of ARF is said to occur in anywhere from $1 \%$ to $25 \%$ of critically ill patients $[1,2]$, depending on the population being studied and the criteria used to define its presence. Furthermore, mortality in these populations ranges from $28 \%$ to $90 \%[10,11]$. Clearly, trials of prevention and therapy are not comparable because widely disparate definitions have been used. However, most definitions of ARF have common elements, including the use of serum creatinine and, often, urine output. Although the kidney has numerous functions, these are the only functions that are routinely and easily measured and that are unique to the kidney.

The accuracy of a creatinine clearance measurement (even when collection is complete) is limited because as glomerular filtration rate (GFR) falls creatinine secretion is increased, and thus the rise in serum creatinine is less $[12,13]$. Thus, creatinine excretion is much greater than the filtered load, resulting in a potentially large overestimation of the GFR (as much as a twofold difference) [13]. However, for clinical purposes it is important to determine whether renal function is stable or 
Figure 1

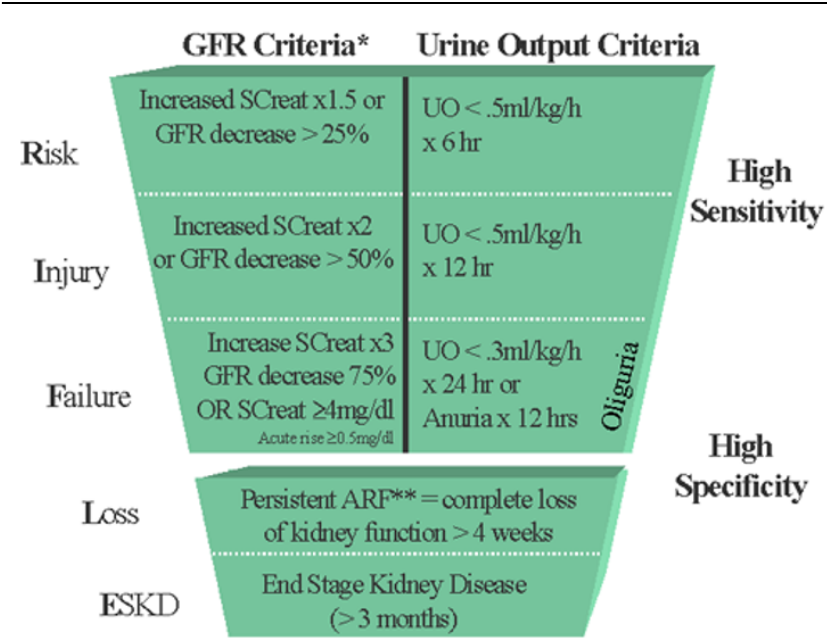

Proposed classification scheme for acute renal failure (ARF). The classification system includes separate criteria for creatinine and urine output (UO). A patient can fulfill the criteria through changes in serum creatinine (SCreat) or changes in UO, or both. The criteria that lead to the worst possible classification should be used. Note that the F component of RIFLE (Risk of renal dysfunction, Injury to the kidney, Failure of kidney function, Loss of kidney function and End-stage kidney disease) is present even if the increase in SCreat is under threefold as long as the new SCreat is greater than $4.0 \mathrm{mg} / \mathrm{dl}(350 \mu \mathrm{mol} / \mathrm{l})$ in the setting of an acute increase of at least $0.5 \mathrm{mg} / \mathrm{dl}(44 \mu \mathrm{mol} / \mathrm{l})$. The designation RIFLE- $F_{C}$ should be used in this case to denote 'acute-onchronic' disease. Similarly, when theRIFLE-F classification is achieved by $\mathrm{UO}$ criteria, a designation of RIFLE- $\mathrm{F}_{\mathrm{O}}$ should be used to denote oliguria. The shape of the figure denotes the fact that more patients (high sensitivity) will be included in the mild category, including some without actually having renal failure (less specificity). In contrast, at the bottom of the figure the criteria are strict and therefore specific, but some patients will be missed. ${ }^{*}$ GFR $=$ Glomerular Filtration Rate; ARF Acute Renal Failure

getting worse or better. This can usually be determined by monitoring serum creatinine alone [14]. Like creatinine clearance, the serum creatinine will not be an accurate reflection of GFR in the non-steady-state condition of ARF. Nonetheless, the degree to which serum creatinine changes from baseline will reflect the change in GFR. Serum creatinine is readily and easily measured and it is specific for renal function, while urea (or blood urea nitrogen) is a nonspecific marker of renal function, making it a poor marker relative to creatinine. Urine output is far less specific, except when it is severely decreased or absent. Severe ARF can exist despite normal urine output (i.e. nonoliguric) but changes in urine output can occur long before biochemical changes are apparent.

In addition, we considered that the following features would be important in any definition of ARF: it should consider change from baseline; it should include classifications for acute on chronic renal disease; it should be easy to use and clinically applicable across different centres; and it should consider both sensitivity and specificity because of different popula- tions and research questions. A classification system should therefore include and separate mild (or early) and severe (or late) cases. This will allow such a classification to detect patients in whom renal function is mildly affected (high sensitivity for the detection of kidney malfunction but limited specificity for its presence) and patients in whom renal function is markedly affected (high specificity for true renal dysfunction but limited sensitivity in picking up early and subtler loss of function). Accordingly, we advocate a multilevel classification system in which a wide range of disease spectra can be included.

The resulting classification scheme, based on the above considerations, is shown in Fig. 1. In addition to the three levels of renal dysfunction, the RIFLE (acronym indicating Risk of renal dysfunction; Injury to the kidney; Failure of kidney function, Loss of kidney function and End-stage kidney disease) criteria also include two clinical outcomes: 'loss' and 'end-stage renal disease' (ESRD). These are separated to acknowledge the important adaptations that occur in ESRD that are not seen in persistent ARF. Persistent ARF (loss) is defined as need for renal replacement therapy (RRT) for more than 4 weeks, whereas ESRD is defined by need for dialysis for longer than 3 months.

Of course, many patients may present with acute renal dysfunction without any baseline measure of renal function. This presents a problem for a system that considers the change from baseline. One option is to calculate a theoretical baseline serum creatinine value for a given patient assuming a given normal GFR. By normalizing the GFR to the body surface area, a GFR of approximately $75-100 \mathrm{ml} / \mathrm{min}$ per $1.73 \mathrm{~m}^{2}$ can be assumed [15], and thus a change from baseline can be estimated for a given patient. The simplified 'modification of diet in renal disease' (MDRD) formula provides a robust estimate of GFR relative to serum creatinine based on age, race and sex [15]. Thus, given a patient without known renal disease but in whom a baseline creatinine is unknown, one can estimate the baseline creatinine. Table 1 solves the MDRD equation for the lower end of the normal range (i.e. $75 \mathrm{ml} / \mathrm{min}$ per $1.73 \mathrm{~m}^{2}$ ). Note that the MDRD formula is used only to estimate the baseline when it is not known. For example, a 50-year-old black female would be expected to have a baseline creatinine of 1.0 $\mathrm{mg} / \mathrm{dl}(88 \mu \mathrm{mol} / \mathrm{l})$.

\section{Clinical outcome measures for ARF studies}

Appropriate selection and definition of outcome measures (end-points) are critical for the successful execution of clinical trials. An outcome is defined as either a measurement (i.e. serum creatinine) or an event (i.e. death or need for dialysis) that is potentially modifiable by a defined intervention. Several criteria must be considered in the selection of outcome measures, including clinical importance, responsiveness to the intervention, precision of their definition, accuracy of measurement and completeness of ascertainment. Because multiple 
Table 1

\begin{tabular}{lllll}
\hline \multicolumn{2}{l}{ Estimated baseline creatinine } \\
\hline Age (years) & Black males $(\mathrm{mg} / \mathrm{dl}[\mu \mathrm{mol} / \mathrm{l})$ & Other males $(\mathrm{mg} / \mathrm{dl}[\mu \mathrm{mol} / \mathrm{l})$ & Black females $(\mathrm{mg} / \mathrm{dl}[\mu \mathrm{mol} / \mathrm{l})$ & Other females $(\mathrm{mg} / \mathrm{dl}[\mu \mathrm{mol} / \mathrm{l})$ \\
\hline $20-24$ & $1.5(133)$ & $1.3(115)$ & $1.2(106)$ & $1.0(88)$ \\
$25-29$ & $1.5(133)$ & $1.2(106)$ & $1.1(97)$ & $1.0(88)$ \\
$30-39$ & $1.4(124)$ & $1.2(106)$ & $1.1(97)$ & $0.9(80)$ \\
$40-54$ & $1.3(115)$ & $1.1(97)$ & $1.0(88)$ & $0.9(80)$ \\
$55-65$ & $1.3(115)$ & $1.1(97)$ & $1.0(88)$ & $0.8(71)$ \\
$>65$ & $1.2(106)$ & $1.0(88)$ & $0.9(80)$ & $0.8(71)$
\end{tabular}

Estimated glomerular filtration rate $=75\left(\mathrm{ml} / \mathrm{min}\right.$ per $\left.1.73 \mathrm{~m}^{2}\right)=186 \times\left(\right.$ serum creatinine $\left.\left[\mathrm{S}_{\mathrm{Cr}}\right]\right)-1.154 \times(\mathrm{age})-0.203 \times(0.742$ if female) $\times$ $(1.210$ if black $)=\exp \left(5.228-1.154 \times \ln \left[S_{C_{r}}\right]\right)-0.203 \times \ln ($ age $)-(0.299$ if female $)+(0.192$ if black $)$.

outcomes may be affected by a single intervention, a hierarchical ranking is required. It is critical that the primary outcome be prospectively identified.

Patient survival (or its reciprocal, mortality) has commonly been used as the primary end-point in clinical trials of RRT in ARF, although the timing has varied [16-18]. In critically ill patients without ARF, 28-day survival may miss more than $20 \%$ of acute mortality [19]. In ARF, a stable survival rate is not achieved until after 30-60 days [20,21]. Several scoring systems for assessment of organ dysfunction and morbidity have been validated in the general ICU population [22-25] and have also been used on ARF patients, although validation studies in the ARF setting are rare. No internationally validated ARF-specific scoring systems exist.

Recovery from ARF can only be evaluated in the context of a specific definition of ARF. We propose that recovery may be partial or complete. Complete renal recovery exists if the patient returns to their baseline classification within the RIFLE criteria, whereas partial renal recovery exists if there is a persistent change in RIFLE classification ( $\mathrm{R}$, I or F) but not persistent need for RRT.

\section{Physiological end-points for ARF studies}

Lack of significant progress in the prevention and management of ARF has been attributed, in part, to failure to identify suitable physiological surrogate end-points for use in research studies testing the efficacy of new interventions. In fact, very few ARF studies have even demonstrated a beneficial effect on the most commonly used physiological end-points, namely the serum urea nitrogen and creatinine concentrations. We compared and critiqued a number of physiological end-points (Table 2).

Because there are no pharmacotherapies that have been proven to alter clinical endpoints (dialysis, mortality) in patients with ARF, it cannot be discerned what changes in currently available serum GFR markers (urea, creatinine) are predictive in smaller phase II studies of success in subsequent phase III trials with clinical end-points. Thus, strategies for ARF prevention and therapy will need to continue to be based on results from studies (positive and negative) using surrogate endpoints (creatinine, urea) until definitive studies demonstrating effectiveness in altering clinical end-points are available. However, clinical decisions based on such evidence should be made cautiously and limited to the use of true surrogates (those that correlate with clinical outcomes). For example, urine output and renal blood flow are not reliable surrogates for outcome in studies of ARF and should not be used as such.

Although some data suggest the utility of urinary electrolyte or other chemistries in the differential diagnosis of ARF, none of these methods has proven reliable in clinical practice [26]. It is unproven whether urine chemistries or microscopy are appropriate indices of renal function for efficacy studies for ARF prevention or therapy. We wish to emphasize that, in the end, interventions must be demonstrated to change major outcomes (survival or recovery of renal function) before they can be recommended for clinical use.

\section{Animal models of ARF}

We fully adopt the general recommendations, outlined by Piper and colleagues [27], in planning, conducting and critically evaluating studies utilizing animal models. Table 3 summarizes these principles and other guidelines for the use of animal models in the study of ARF. Despite their limitations, animal models remain fundamental to improving our understanding of human ARF [28-30].

There are three basic types of animal models in use for study of ARF: ischemia; toxins and sepsis models; and several subtypes. Each has its own advantages and disadvantages, which are summarized in Table 4. No one model has been shown to be universally applicable to the study of ARF. Indeed, no model currently available provides a reproducible model of clinical ARF as seen in the critically ill. Better models are needed. 
Table 2

\begin{tabular}{|c|c|c|c|}
\hline Specific for & Measurable & Acceptable? ${ }^{1}$ & Realistic/time-related? ${ }^{2}$ \\
\hline \multirow[t]{10}{*}{ GFR } & $\mathrm{PAH}$ & No & No \\
\hline & Creatinine & Yes & Yes \\
\hline & \multirow[t]{2}{*}{ Creatinine clearance } & 2-hour: yes & Yes \\
\hline & & 24-hour: yes & No \\
\hline & BUN & Yes & Yes \\
\hline & Inulin clearance & Yes & No \\
\hline & lohexol/iopromide & Yes & Yes \\
\hline & lothalmate & Yes & Yes \\
\hline & I131-MAG & Yes & No \\
\hline & Cr ${ }^{52-E D T A}$ & Yes & No \\
\hline \multirow[t]{4}{*}{ Renal blood flow } & Angiography & Yes & No \\
\hline & Indicator dilution (thermal or $\mathrm{PAH}$ ) & Yes & No \\
\hline & BOLD MRI & Yes & No \\
\hline & Ultrasound & Yes & Yes \\
\hline \multirow[t]{7}{*}{ Tubular function } & Urine output & Yes & Yes \\
\hline & Input-output balance & Yes & Yes \\
\hline & Urinalysis & Yes & Yes \\
\hline & $\mathrm{FeNa}$ & Yes & Yes \\
\hline & Osmolality & Yes & Yes \\
\hline & Creatinine (U/P) & Yes & Yes \\
\hline & Tubular proteins & No & No \\
\hline
\end{tabular}

'The term 'acceptable' refers to the consensus view that each one of these tests represents a marker that reflects the function being measured with sufficient specificity and sensitivity for experimental and clinical use. ${ }^{2}$ The term 'realistic' refers to consensus of the current feasibility of using such markers in clinical practice. BOLD, blood oxygenation level dependent; BUN, blood urea nitrogen; MRI, magnetic resonance imaging; PAH, para-aminohippuric acid; U/P, urine/plasma.

\section{Techniques for assessing and achieving fluid balance in ARF}

Fluid therapy, together with attention to oxygen supply, is the cornerstone of resuscitation in all critically ill patients. It is important to recognize that fluid deficits can occur in the absence of obvious fluid loss because of vasodilation or alterations in capillary permeability. Hypovolaemia results in inadequate blood flow to meet the metabolic requirements of the tissues and must be treated urgently if ARF is to be avoided [31,32]. Special attention to volume status is therefore required in patients at risk for ARF. Although the importance of fluid management is generally recognized, the choice and amount of fluid, and assessment of fluid status are controversial [33-35]. Whereas volumetric parameters are more reliable for detecting intravascular volume changes, pressure monitoring may be more important for prevention of pulmonary oedema. Clinical assessment of peripheral oedema, body weight and radiological evaluation remain the most widely used parameters for detecting interstitial fluid excess. Objec- tive assessment of extravascular lung water can be achieved with transpulmonary indicator dilution [36-40]. One recent study conducted in the emergency department on patients with sepsis [41] found an improvement in outcome using a resuscitation strategy ('early goal-directed' therapy), which involved the use of continuous central venous oxygen measurement. It is not known whether the monitoring method was a necessary or sufficient component of the intervention. A much larger study in much less sick, general surgery patients [42] found no benefit from routine pulmonary artery catheterization.

\section{Information technology and acute dialysis}

The goals of information technology in its application to acute dialysis therapy are to improve our understanding of current practice and to improve patient care. In order to achieve these goals, six areas of focus were identified: patient safety, current practice pattern assessment, practice variation, patient assessment, dialysis machine technology and clinical trials. Medical errors have repeatedly been shown to affect patient 
Critical Care August 2004 Vol 8 No 4 Bellomo et al.

Table 3

Principles that should guide the development and study of animal models of acute renal failure

General principles that must be applied to design of animal model

Proper randomization of animals

Similar baseline characteristics of the experimental groups

Concurrent appropriate controls

Blinded assessment of outcome

Consideration and reporting of mortality

Numbers of animals studied should be appropriate to reproducibility of outcome measure
Additional issues that must be considered to optimize the model

Models should be chosen on the basis of their relevance to the clinical situation, and not merely by the reproducibility of the model

Physiological parameters known to affect kidney function or susceptibility to injury should be controlled for, measured and reported (temperature, blood pressure, fluid status, type of anaesthesia, etc.)

Appropriate preparation of tissue for valid pathological interpretation

Fundamental requirements for a model should include morphology, haemodynamics and function

Outcomes should be measures at multiple time points

Noninvasive biomarkers for renal parenchymal cell injury should be developed

Models should be created that explicitly address comorbidities that are believed to predispose to acute renal failure and outcome in humans

Experimental observations should be reproduced in other laboratories before they are generally accepted

\section{Table 4}

A comparison of leading animal models for the study of acute renal failure

\begin{tabular}{|c|c|c|c|c|c|c|c|c|c|c|c|}
\hline Model & Simple & Reproducible & $\begin{array}{l}\text { Complete } \\
\text { control } \\
\text { over } \\
\text { external } \\
\text { factors }\end{array}$ & $\begin{array}{l}\text { Graded } \\
\text { response } \\
\text { easily } \\
\text { achieved }\end{array}$ & Tubular & Medullary & $\begin{array}{l}\text { Inflam- } \\
\text { mator } y^{1}\end{array}$ & $\begin{array}{l}\text { Functiona } \\
\text { I injury } \\
\text { and } \\
\text { pathology } \\
\text { correlate }\end{array}$ & $\begin{array}{l}\text { Matches } \\
\text { human } \\
\text { pathology }\end{array}$ & $\begin{array}{l}\text { Matches } \\
\text { clinical } \\
\text { scenario }\end{array}$ & $\begin{array}{l}\text { Clinical } \\
\text { Relevance }\end{array}$ \\
\hline $\begin{array}{l}\text { Warm } \\
\text { ischaemia }^{2}\end{array}$ & + & + & & + & + & + & + & + & & & \pm \\
\hline $\begin{array}{l}\text { Isolated } \\
\text { perfused } \\
\text { kidney }\end{array}$ & & + & + & + & + & \pm & & & & & \\
\hline $\begin{array}{l}\text { Radio } \\
\text { contrast }\end{array}$ & + & & & & + & + & + & + & + & + & + \\
\hline $\begin{array}{l}\text { Combined } \\
\text { insults }\end{array}$ & & & & & + & + & + & \pm & \pm & + & + \\
\hline Gentamicin & + & + & & & \pm & & & & \pm & + & + \\
\hline Cisplatin ${ }^{3}$ & + & + & & & + & & & & + & + & \pm \\
\hline Glycerol4 & + & + & & & + & & + & & & & + \\
\hline $\begin{array}{l}\text { Myoglobin/ } \\
\text { haemaglobin }\end{array}$ & + & & & & & & & & & & + \\
\hline Endotoxin & + & + & & + & & & + & & & & \\
\hline $\begin{array}{l}\text { Bacterial } \\
\text { infusion (iv) }\end{array}$ & + & & & & & & + & & & & + \\
\hline $\begin{array}{l}\text { Bacterial } \\
\text { infusion (ip) }\end{array}$ & + & & & & & & + & & & & + \\
\hline $\begin{array}{l}\text { Caecal } \\
\text { perforation }\end{array}$ & + & & & & & & + & & & + & + \\
\hline
\end{tabular}

In the first column a list of recognized models used for the study of acute renal failure is presented. Then, in each column, an evaluation is presented regarding whether a given model contains certain features. ' + ' Indicates the presence of a given feature; ' \pm ' indicates only the partial presence of that feature; and the absence of any sign indicates the lack of such a feature. For example, warm ischemia is simple but does not match the dominant clinical scenario and is of limited clinical relevance. ${ }^{1}$ Reproduces the type of injury seen in humans. ${ }^{2}$ Cold ischaemia is more clinically relevant to renal transplantation, but it is less well characterized. ${ }^{3}$ Clinical relevance is limited because less toxic alternatives are now available. ${ }^{4}$ Resembles clinical rhabdomyolysis. 


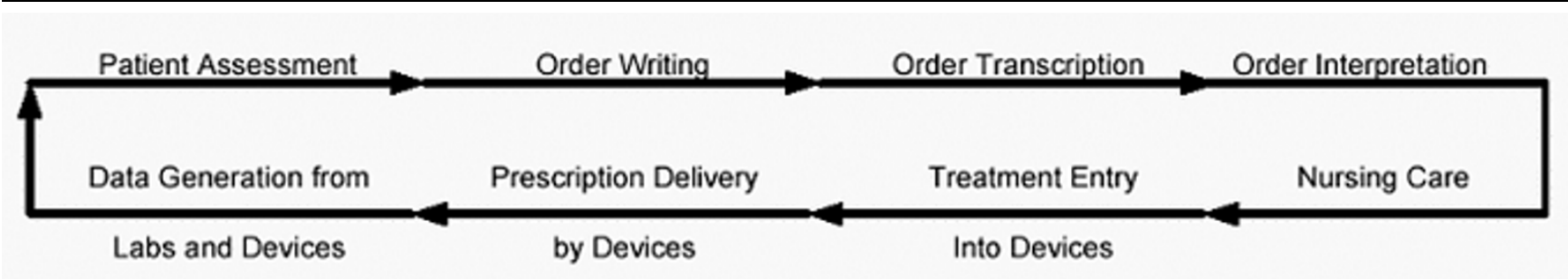

The cycle of patient care and sites of potential errors. Any step in this continuous cycle of assessing and caring for a patient can be a site of error, which may lead to patient harm.

morbidity and mortality significantly. In numerous fields information technology has been applied to work flow processes to minimize deviations from planned procedures $[43,44]$. No studies are currently available that document potential sources of error in the acute dialysis setting. In delivery of acute dialysis care, errors may occur anywhere within the work flow process (Fig. 2). The characteristics of each of these stages may prevent or predispose to potential errors, which may lead to patient harm. We recommend that newer methods for decreasing errors include real-time analysis of centralized patient information repositories to detect deviations or conflicts in intended care and computerized physician order entry. We also recommend that computerized provider order entry be progressively introduced, with consistent and predictable prompting for the parameters needed for therapy. In such computerized provider order entry, all new orders should be cross-checked against acceptable treatment parameters and compared with known patient data to determine whether potential conflicts may occur [45].

The most common method used to control practice variation within centres is by policy. Because in ARF the indications and methods for therapy have not adequately been determined, policies will need to remain flexible. Currently, no formal certification process exists to quantify competency. Computer technology can improve this area by creating simulated therapy sessions that both train and assess the skills of the nurses.

The human-machine interaction can also be improved. Machine displays should make it easy for the provider to detect the signal carrying the information about a patient's status from within the large quantity of excess noise presented by less useful data [46]. Such display technology should be easy to read, easy to navigate and customizable for a specific user's needs or role. This could be accomplished either by displaying covariant variables simultaneously in a graph such as fluid balance and central venous pressure, or by displaying indices of patient status. These indices would represent validated summaries of multiple variables, which relate to a validated surrogate outcome marker such as a severity index. Currently, most dialysis devices operate independently from the information infrastructure within institutions. Focusing on integration with the information infrastructure should facilitate many of the key steps necessary for improved care. The dialysis machine should contribute information to automated assessment of patients and thus should be interfaced to such systems.

\section{Discussion}

We found sufficient consensus on 47 questions to allow the development of recommendations. Importantly, we were able to reach broad consensus on a definition for $A R F$ and various aspects of ARF research, including outcome measures and animal models. Full versions of the six workgroups' findings are available on the internet http://www.ADQl.net.

We hope that the results of this consensus process will help to standardize the study of ARF, both for prevention and treatment. Indeed, it must be understood that although our recommendations are based, to the best extent possible, on data, there are insufficient data to guide many important decisions. As a result, our findings should be considered a 'first step' in the process of standardization. For example, the RIFLE criteria for diagnosis of ARF will need to be validated in large patient series - efforts that are currently underway.

In addition, we recognize that some of our recommendations may seem arbitrary or attempt to balance utility and precision in a way that may limit both. For example, therapy can influence the primary criteria for the diagnosis of ARF. Hydration status will influence urine output and, to some degree, may even alter the volume of distribution for creatinine. Large dose diuretics may be used to force a urine output when it would otherwise fall into a category consistent with a diagnosis of ARF. Such influences are unavoidable and analogous to those in other disease processes, which require clinical classification. Similarly, one might hypothesize that the underlying disease process that results in ARF (e.g. radiocontrast versus sepsis) will alter the 'clinical meaning' of each degree of renal dysfunction. However, by applying the present criteria across these various aetiologies, it will be possible to test this hypothesis directly. It should also be noted that these criteria were developed to describe ARF occurring in the critically ill. Primary renal diseases such as glomerulonephritis should be excluded from this classification system. The ultimate value of a definition for 
ARF will be determined by its utility. A classification scheme for ARF should be sensitive and specific, and predictive of relevant clinical outcomes such as mortality and length of hospital stay. These too are testable hypotheses. Thus, despite limited data, broad areas of consensus exist for the physiological and clinical principles needed to guide the development of a consensus definition of ARF. They also exist for the need to evolve ARF models toward greater reproduction of common clinical scenarios, principles and monitoring technology of fluid therapy, choice of physiological and clinical endpoints for trials, and the possible role of information technology.

\section{Key messages}

The first consensus definition of acute renal failure (ARF) has now been developed. It is called RIFLE, the initials reflecting the terms Risk, Injury, Failure, Loss and End Stage in relation to kidney function. It is presented in this article.

The body responsible for the consensus definition of ARF is the Acute Dialysis Quality Initiative (ADQI) group, which conducted a consensus conference for this purpose.

The ADQI group reviewed animal models of ARF and classified them according to their features, usefulness, relevance and reproducibility. They are summarized in Table 4.

The ADQI group reviewed the issue of end-points for trials or studies in ARF and summarized the advantages and disadvantages of different end-point in different investigational situations.

The ADQI group reviewed issues of technology as they relate to the treatment of acute renal failure and developed general principles for future developments in renal support technology.

All issues are discussed in details on the webpage of ADQI http://www.ADQl.net

\section{Competing interests}

None declared.

\section{Additional material}

\section{Appendix 1}

Members of the ADQI Workgroup.

see

[http://www.biomedcentral.com/content/supplementary/cc2872-

S1.pdf]

\section{References}

1. Chertow GM, Levy EM, Hammermeister KE, Grover F, Daley J: Independent association between acute renal failure and mortality following cardiac surgery. JAMA 1998, 104:343-348.

2. de Mendonca A, Vincent JL, Suter PM, Moreno R, Dearden NM, Antonelli M, Takala J, Sprung C, Cantraine F: Acute renal failure in the ICU: risk factors and outcome evaluation by SOFA score. Intensive Care Med 2000, 26:915-921.

3. Bellomo R, Kellum JA, Ronco C: Acute renal failure: time for consensus. Intensive Care Med 2001, 27:1685-1688.

4. Rosen S, Heyman SN: Difficulties in understanding human 'acute tubular necrosis': limited data and flawed animal models. Kidney Int 2001, 60:1220-1224.

5. Erley CM, Bader BD, Berger ED, Vochazer A, Jorzik JJ, Dietz K Risler T: Plasma clearance of iodine contrast media as a measure of glomerular filtration rate in critically ill patients. Crit Care Med 2001, 29:1544-1550.

6. Ragaller MJ, Theilen $\mathrm{H}$, Koch $\mathrm{T}$ : Volume replacement in critically ill patients with acute renal failure. J Am Soc Nephrol 2001 Suppl 17:S33-S39.

7. Vella K, Goldfrad C, Rowan K, Bion J, Black N: Use of consensus development to establish national research priorities in critical care. BMJ 2000, 320:976-980.

8. Chestnut RM: Implications of the guidelines for the management of severe head injury for the practicing neurosurgeon Surg Neurol 1998, 50:187-193.

9. Kellum JA, Ramakrishnan N, Angus D: Appraising and using evidence in critical care. In Textbook of Critical Care Edited by: Grenvik A, Ayers SM, Holbrook PR, Shoemaker WC. Philadelphia, WB: Saunders; 2000:2059-2070.

10. Metnitz PG, Krenn CG, Steltzer H, Lang T, Ploder J, Lenz K, Le Gall $J R$, Druml W: Effect of acute renal failure requiring renal replacement therapy on outcome in critically ill patients. Crit Care Med 2002, 30:2051-2058.

11. Consentino $F$, Chaff $C$, Piedmonte M: Risk factors influencing survival in ICU acute renal failure. Nephrol Dial Transplant 1994, 9:179-182.

12. Erley CM, Bader BD, Berger ED, Vochazer A, Jorzik JJ, Dietz K, Risler T: Plasma clearance of iodine contrast media as a measure of glomerular filtration rate in critically ill patients. Crit Care Med 2001, 29:1544-1550.

13. Doolan PD, Alpen EL, Theil GB: A clinical appraisal of the plasma concentration and endogenous clearance of creatinine. Am J Med 1962, 32:65-72.

14. Kim KE, Onesti G, Ramirez O: Creatinine clearance in renal disease. A reappraisal. $B M J$ 1969, 14:11-19.

15. National Kidney Foundation: K/DOQI Clinical Practice Guidelines for Chronic Kidney Disease: Evaluation, Classification and Stratification. Am J Kidney Dis 2002, 39: 2 Suppl 1:S76-S92.

16. Ronco C, Bellomo R, Homel P, Brendolan A, Dan M, Piccinni P, La Greca G: Effects of different doses on continuous venovenous haemofiltration on outcomes of acute renal failure: a prospective randomised trial. Lancet 2000, 356:26-30.

17. Schiffl $H$, Lang SM, Fischer R: Daily hemodialysis and the outcome of acute renal failure. N Engl J Med 2002, 346:305-310.

18. Mehta RL, McDonald B, Gabbal FB, Pahl M, Pascual MTA, Farkas A, Kaplan RM: A randomized clinical trial of continuous versus intermittent dialysis for acute renal failure. Kidney Int 2001 60:1154-1163.

19. Capuzzo M, Valpondi V, Zardi S, Belin M, De Luca S, Alvisi R: Mortality of intensive care patients: at a fixed point in time or in the hospital? Intensive Care Med 2001, Suppl 2:A367.

20. Himmelfarb J, Tolkoff Rubin N, Chandran P, Parker RA, Wingard RL, Hakim R: A multicenter comparison of dialysis membranes in the treatment of acute renal failure requiring dialysis. $J A m$ Soc Nephrol 1998, 9:257-266.

21. Gastaldello K, Melot C, Kahn RJ, Vanherweghem JL, Vincent JL, Tielemans C: Comparison of cellulose diacetate and polysulfone membranes in the outcome of acute renal failure. A prospective randomized study. Nephrol Dial Transplant 2000 15:224-230.

22. Vincent JL, Mendonca A, Cantraine F, Moreno R, Takala J, Suter $\mathrm{PM}$, Sprung CL, Colardyn F, Blecher S: Use of the SOFA score to assess the incidence of organ dysfunction/failure in inten- 
sive care units: results of a multicenter, prospective study. Crit Care Med 1998, 26:1793-1800.

23. Le Gall JR, Klar J, Lemeshow S, Saulnier F, Alberti C, Artigas A, Teres $D$ : The logistic organ dysfunction system. A new way to assess organ dysfunction in the intensive care unit. JAMA 1996, 276:802-810.

24. Le Gall JR, Lemeshow St, Saulnier F: A new simplified acute physiology score (SAPS II) based on a European/North American multicenter study. JAMA 1993, 270:2957-2963.

25. Knaus WA, Draper EA, Wagner DP, Zimmermann JE: APACHE II: a severity of disease classification system. Crit Care Med 1985, 13:818-829.

26. Zarich S, Fang LS, Diamond JR: Fractional excretion of sodium: exceptions to its diagnostic value. Arch Intern Med 1985, 145:108-112.

27. Piper RD, Cook DJ, Bone RC, Sibbald WJ: Introducing critical appraisal to studies of animal models investigating novel therapies in sepsis. Crit Care Med 1996, 24:2059-2070.

28. Wan L, Bellomo R, Di Giantomasso D, Ronco C: The pathogenesis of septic acute renal failure. Curr Opin Crit Care 2003, 9:496-502.

29. Heyman SN, Rosen S, Darmon D, Goldfarb M, Bitz H, Shina A, Brezis M: Endotoxin-induced renal failure: II. A role for tubular hypoxic damage. Exp Nephrol 2000, 8:275-282.

30. Wichterman KA, Baue AE, Chaudry IH: Sepsis and septic shock: a review of laboratory models and a proposal. J Surg Res 1980, 29:189-201.

31. Blow O, Magliore L, Claridge JA, Butler K, Young JS: The golden hour and the silver day: detection and correction of occult hypoperfusion within $\mathbf{2 4}$ hours improves outcome from major trauma. J Trauma 1999, 47:964-969.

32. Claridge JA, Crabtree TD, Pelletier SJ, Butler K, Sawyer RG Young JS: Persistent occult hypoperfusion is associated with a significant increase in infection rate and mortality in major trauma patients. J Trauma 2000, 48:8-15.

33. Michard F, Boussat S, Chemla D, Anguel N, Mercat A, Lecarpentier Y, Richard C, Pinsky MR, Teboul J: Relation between respiratory changes in arterial pulse pressure and fluid responsiveness in septic patients with acute circulatory failure. Am J Resp Crit Care Med 2000, 162:134-138.

34. Pinsky MR: Functional hemodynamic monitoring. Intensive Care Med 2002, 28:386-388.

35. Pinsky MR: Pulmonary artery occlusion pressure. Intensive Care Med 2003, 29:19-22.

36. Ely EW, Smith AC, Chiles C, Aquino SL, Harle TS, Evans GW, Haponik EF: Radiologic determination of intravascular volume status using portable, digital chest radiography: a prospective investigation in 100 patients. Crit Care Med 2001, 29:1502-1512.

37. Martin GS, Ely EW, Carroll FE, Bernard GR: Findings on the portable chest radiograph correlate with fluid balance in critically ill patients. Chest 2002, 122:2087-2095.

38. Sakka SG, Klein M, Reinhart K, Meier-Hellmann A: Prognostic value of extravascular lung water in critically ill patients. Chest 2002, 122:728-734.

39. Mitchell JP, Schuller D, Calandrino FS, Schuster DP: Improved outcome based on fluid management in critically ill patients requiring pulmonary artery catheterization. Am Rev Respir Dis 1992, 145:990-998.

40. Ferguson ND, Meade MO, Hallett DC, Stewart TE: High values of the pulmonary artery wedge pressure in patients with acute lung injury and acute respiratory distress syndrome. Intensive Care Med 2002, 28:1073-1077.

41. Rivers E, Nguyen B, Havstad S, Ressler J, Muzzin A, Knoblich B, Peterson E, Tomlanovich for the Early Goal-Directed Therapy Collaborative Group: Early goal-directed therapy in the treatment of severe sepsis and septic shock. N Engl J Med 2001, 345:1368-1377.

42. Sandham JD, Hull RD, Brant RF, Knox L, Pineo GF, Doig CJ, Laporta DP, Viner S, Passerini L: A randomized controlled trial of the use of pulmonary-artery catheters on high risk surgical patients. N Engl J Med 2003, 348:5-14.

43. Spencer FC: Human error in hospitals and industrial accidents: current concepts. J Am Coll Surg 2000, 191:410-418.

44. Sexton JB, Thomas EJ, Helmreich RL: Error, stress, and teamwork in medicine and aviation: cross sectional surveys. $B M J$ 2000, 320:745-749.
45. Morris $\mathrm{AH}$ : Computerized protocols and bedside decision support. Crit Care Clin 1999, 15:523-545.

46. Simkus R: Application of an intelligent graphical interface to electronic patient records. Medinfo 2001, 10:690-692. 